\title{
“ALUDIR É MELHOR QUE NOMEAR”: A LEITURA E A ALUSÃO NO TEXTO LITERÁRIO
}

\author{
Vânia Lucia Menezes Torga ${ }^{1}$
}

Resumo: Estudo sobre leitura, ensino e aprendizagem e intertextualidade e tem como objetivo investigar o movimento de sentido da alusão na construção de uma teoria de leitura que contempla as estratégias textuais que delineiam o projeto de leitor proposto pelos autores estudados, quando o produto fala ao mesmo tempo do processo em algumas obras literárias como "Ler, escrever e fazer conta de cabeça, "Por Parte de Pai" e "Ciganos" de Bartolomeu Campos Queirós e "O Risco do bordado" de Autran Dourado. A organização teórico-metodológica da leitura se dá sob a perspectiva da relação de simetria/assimetria proposta pelas estratégias textuais, distribuídas pelas categorias da memória, metáfora/metonímia na articulação lingüísticosemântica que operacionaliza a produção da alusão, a partir de Bakhtin, Amorim, Campos, Gagnebin, Torga, Authier-Revuz, Eco, Walty, Cury e Paulino, Kosik que dão suporte ao estudo.

Palavras-chave: Alusão, Leitura, Ensino, Aprendizagem, Literatura.

Abstract: This paper is a study of reading, learning and teaching, and intertextuality, whose aim is to investigate the movement of the sense of allusion in the construction of a reading theory that takes into consideration textual strategies which are responsible for sketching the features of the image of the reader proposed by the authors studied, in a situation where the product itself makes reference to the process in some literary works, such as: "Ler, escrever e fazer conta de cabeça", "Por Parte de Pai" and "Ciganos" by Bartolomeu Campos Queirós and "O Risco do Bordado" by Autran Dourado. The theoretical and methodological approach relies on the perspective of the relation of symmetry/asymmetry proposed in the context of textual strategies, distributed through the categories of memory, metaphor/metonymy in a linguistic-semantic articulation which is responsible for the production of allusion. This study is underpinned by authors such as: Bakhtin, Amorim, Campos, Gagnebin, Torga, Authier-Revuz, Eco, Walty, Cury and Paulino, and Kosik.

Key words: Allusion, Reading, Learning and Teaching, Literature.

Minhas pesquisas, a respeito dos gêneros discursivos, da leitura e escrita do romance, têm como organização teórico-metodológica a perspectiva da relação de simetria/assimetria, proposta pelas estratégias textuais de quem escreve e de quem lê. Assim, meu trabalho de construção de uma teoria de leitura com a alusão, na qualidade de estratégia de leitura do texto literário, tem sido o de delinear o

1 Professora da Universidade Estadual de Santa Cruz - UESC. Endereço eletrônico: vltorga @uol.com.br. 
leitor-modelo e o autor-modelo, dimensionados entre outras categorias, pela memória - memória-sonho, memória-trabalho (lembrança/esquecimento), metáfora e metonímia, na articulação lingüístico-semântica que operacionaliza a alusão, nas obras que têm constituído os corpora das pesquisas e orientações.

A alusão é a estratégia mediadora dos movimentos da intertextualidade. A intertextualidade é espaço contraditório da memória: o esquecer, recriado; o lembrado, reestruturado, em que fica o que significa, reproduzido pela transformação. A memória não reproduz absolutamente o que foi, mas refaz o passado, reconstrói o vivido sob o olhar do tempo presente que não é apenas individual, mas social. Exige esse trabalho de transformação, mas, como num palimpsesto, conserva, relativamente, as características do todo de que é parte e do qual a memória faz o recorte ao lembrar o que significa.

Nesse sentido entendo a alusão que, para Paulino, Walty e Cury (1995, p. 29) é um tipo de intertextualidade fraca, uma vez que nota apenas uma leve menção a outro componente seu, minhas pesquisas têm indicado que a alusão, em sendo sutil, é perturbadora, criadora do movimento de ir e vir, devir, exige do leitor um compromisso com a construção da narrativa, que tem uma história e precisa ser por ele reconstruída mnemonicamente pela cooperação.

Eco (1984, p. 99) no seu Seis Passeios pelo bosque da ficção afirma que um texto é um jogo de estratégias mais ou menos como pode ser a disposição de um exército para uma batalha, em que o "comandante" - o autor - dispõe de seus soldados, procurando imaginar um modelo de pensar do seu "oponente" - o leitor - de ser um sujeito que raciocina de tal modo. Para levá-lo a racionar de tal modo, o "comandante" dispõe seus soldados de maneira que o "oponente" seja induzido a racionar e a reagir de tal maneira a imaginar a imagem de como aquele tem a lhe oferecer, através da disposição das tropas. Se seu jogo tiver êxito, o outro reagirá de modo a fazer triunfar seu texto estratégico. Naturalmente, também o outro seu "oponente" - se encontra na mesma situação. Contudo, o "oponente" desenvolve estratégias mais interessantes que aquelas imaginadas pelo "comandante" e obriga a este a comportar-se como estrategista-modelo proposto pelo "oponente".

Então, ao falar de batalha, modelo, imagem, imaginadas, estrategista de certo modo falo daquele que escreve e, assim, constrói, imaginariamente, um certo perfil de autor - certo estilo de escrita. Por outro lado, também ao escrever, projeta-se certo estilo de leitura, certo leitor.

A alusão, estratégia textual, construída como ação de linguagem, indicia que há o movimento de deslocamento do autor/leitor na busca da construção interativa de sentido nas ações do "um" e do "outro", o que se dá via excedência de visão. A excedência de visão, conceito basilar em Bakhtin diz respeito ao processo de produção de sentido que o locutor produz inventando a si como uma certa construção de linguagem, inventando, também, o outro, o interlocutor, como uma 194 A Cor das Letras - UEFS, n. 8, 2007 
construção de linguagem com a qual se viabiliza a interação. Sendo assim o processo alusivo, por se constituir no jogo da reprodução e da transformação de sentidos, constitui aquele excedente, ou seja, aquele projeto de sentido que vai além dos sentidos estabelecidos, constituído pelo cruzamento de sentidos de enunciações diferentes.

Segundo Campos (2004):

O estudo teórico das estratégias textuais da alusão, na qualidade de estilo, pensado como relação autor/leitor - autor-modelo/leitor-modelo - obriga a pensar a produção de sentido do texto como processo de tensão articulado mnemonicamente pelo jogo das forças do esquecimento e da lembrança.

Em Ler, escrever e fažer conta de cabeça temos a história das perdas do meninonarrador adulto e o destramelar as janelas para espiar mais longe o mundo do aprender na escola.

Com a memória do menino-narrador adulto e com a minha memóriatrabalho, como autor empírico, como investigador e pesquisador, ler e escrever me orientam na construção do movimento de sentido da alusão: uma estratégia textual de leitura das obras referidas de onde tiro fragmentos que iluminem o que procuro sustentar - a alusão como teoria de leitura ou como teoria que permite ao leitor destramelar as janelas e espiar mais longe.

Em Ler, escrever e fazer conta de cabeça a grande perda é a mãe, vitimada pelo câncer e é, em torno dessa perda, que tudo acontece: o sofrimento, a dor, as perdas, as faltas, os silêncios que povoam sua vida - familiar e de estudante, futuro profissional. A dor, pela perda da mãe, acompanha o menino, e o jogo alusivo indicia que aprender também dói, aprender a ler e escrever aludem a perdas e ganhos e isto é muito custoso, obrigando a fazer conta de cabeça: "Isso me ensinou que [...] a Matemática também tem suas conveniências” (QUEIRÓS, 1996, p. 90).

Um dia, muito de repente, abri o embrulho. Olhei e li, lentamente, morfina. Um pavor frio tomou conta da minha barriga inteira. [...] a palavra morfina me levou a muitos lugares e a outros exílios (Idem, p. 35-6).

Contrapondo-se a essas perdas, havia a vontade de desamarrar os nós, entrar em acordo com o desconhecido, abrir o caderno limpo e batizar as folhas com a sabedoria do mistério, abrir portas para receber novas lições, destramelar as janelas e espiar mais longe. Tudo isso me encantava (Idem, p. 8).

A escola passa a ser o espaço, o fora, que possibilita a recuperação do afeto e a presença da mãe, na figura da professora:

minha mãe passava horas podando suas mágoas, enterrando suas tristezas, transplantando suas suspeitas. [...] Ninguém tinha maior paciência, melhor sabedoria, mais encanto. [...] A professora olhava, passava a mão em minha cabeça, e 
me pedia para ajudar a distribuir os cadernos ou para passar o ditado no quadro (Idem, p. 73; 44 e 53).

Nessa obra, Bartolomeu Campos Queirós, utilizando-se da memóriatrabalho e transfigurando-a em memória-sonho, memória-poética, revive as instituições de socialização (escola, igreja, vizinhança) que povoam a vida do meninonarrador adulto e que representam de um lado, no seu processo de socialização, de preparação para o mundo adulto, o lugar de ganho, de amor, de proibições, de pecado; de outro lado, a família, como instituição de socialização primária, o lugar do sofrimento, da dor, da falta, do trabalho, dos silêncios, das crenças, do sonho.

A memória-sonho - fator de produção da ciência e arte, de produção intelectual e afetiva - fala do que não existe. Entre o que existe e o que não existe há um fosso, um silêncio que alude à falta, ao desejo. $\mathrm{O}$ sonho vai articular a voz do desejo. E para articular o sistema de significação da memória-sonho, ele precisa rearticular, desarticular o sistema de significação da memória imediata, articulando outro sistema de significação que dá conta da memória mediata.

A memória-trabalho é fator de produção ligado a ação do homem. Articula a relação dos sistemas de significação com a prática cotidiana do homem que é voltada para a produção da riqueza, da sobrevivência, garantindo-se não só a sua acumulação (exploração, distribuição) no plano particular/coletivo, como também a produção da cultura, a investigação e a pesquisa dos estudos lingüísticos articulados com a prática de ler e escrever.

O fragmento de $O$ risco do bordado retrata a impossibilidade absoluta da memória-trabalho, ou seja, não é possível o absoluto perfil do menino do passado, mas tal perfil, ainda que relativamente reproduzido, vai sendo esmaecido, apagado, transgredido pela produção de um outro perfil:

No colégio as coisas se sucediam numa rapidez espantosa: ele crescia. O menino ia ficando pra trás com a ligeireza com que correm os postes do telégrafo vistos de uma janela de trem, engolido pela voracidade do tempo, enterrado nas brumas. Era difícil distinguir detrás da neblina (sucessivas camadas e névoas e vidros embaciados e lágrimas e soalhos antigos) o perfil daquele menino, a figura esmaecendo dia a dia (AUTRAN DOURADO, 1999, p. 54).

A memória-sonho, com a força de produção de sentido pela operação da dispersão, possibilita a convivência com o que vai apagando: a alusão nasce aqui da ambigüidade do que vai sendo apagado como que vai sendo produzido para ser lembrado no presente.

A metodologia fenomenológico-dialética me indiciou o movimento de investigação e pesquisa que acredito ser, ainda, o movimento de sentido da alusão, como uma das estratégias de leitura. Esse percurso se deu por acreditar que tudo está em movimento, em constante transformar-se e que, no pensamento dialético- 
fenomenológico, não há pontos de origem ou de partida, mas que os fenômenos, ou partes, se inter-relacionam e ir conhecendo o todo, é necessário que se vá conhecendo as partes, e isso se dá de forma não linear, mas como uma espiral. $\mathrm{Ou}$ seja, compreender as partes pelo todo que elas vão formando e o todo, não como uma soma, mas uma síntese de partes que vão sendo ligadas entre si. Assim, o fenômeno contém o movimento que revela a essência e essa o movimento que revela o fenômeno e que ambos se articulam cientificamente pelo détour ou giro analítico, no interior da mediação que mobiliza os dois constituintes anteriores.

A constituição de um sentido se dá pela relação dialógica todo/parte/todo que tem na alusão, uma das estratégias de leitura, por exemplo, em Ler, escrever e fazer conta de cabeça.

Morfina me trouxe o altar-mor, com o Cristo crucificado e deitado, morto de dor e chagas, coberto com um cetim roxo e triste, até a cintura. Mas entre mor e morte faltava um pedacinho que estava escrito na noite. Noite que me engolia para o nada [...].

O senhor Morais, com presteza, fervia a seringa na lata, armada como um navio incendiado $[\ldots]$ a morfina apagava o altar-mor, a Josefina, o Mistura Fina, o José, e os ais do senhor Morais [...].

As palavras eram feitas de pedaços, e cabia à gente juntá-los. No escuro com linha escura e cautela, eu ia amarrando as letras, somando partes com cuidado, sem pensar na palavra morfina, para não me aborrecer. E minha mãe, cada dia mais mofina andava sem força para cantar e espantar o pavor (QUEIRÓS, 1997, p. 36-8).

\section{Fenômeno}

morfina / altar-mor, noite, morte / Josefina, Mistura Fina / Sr. Morais, ais / mofina

\section{Mediação}

com linha escura e cautela eu ia amarrando as letras.

3. Essência morfina / mofina

1. Fenômeno

1.1. Morfina- medicamento utilizado para aplacar a dor, que faz a mãe dormir pesado e temporário;

1.2. Altar-mor: altar maior, altar principal da igreja, onde o Cristo traz a dor, a morte simbolizadas pelas chagas, pela cor roxa;

1.3. Morte - fim e começo ou continuação da vida, de acordo com as mais variadas crenças, é o lugar do desconhecido, do mistério;

1.4. Noite - espaço de tempo reservado ao descanso, ao inesperado, à escuridão; 
1.5. Josefina/Mistura Fina, sr. Morais, ais - irmã que tem pedaços de Mistura Fina, marca de cigarro, que sua vez também traz nas misturas finas do tabaco a referência à morte, dor, fim, morfina, mofina. $\mathrm{O}$ sr. Morais é aquele que traz nas partes, os pedaços da dor, da falta, do fim mas também, contraditoriamente, o alívio da dor, no todo que se compõe destas partes.

2. Mediação

2.1. pedaços - partes com propriedades do todo e que se constituem uma alusão ao não-saber do menino-narrador;

2.2. linha escura - instrumento de ação, contraditório, entre o não-saber pedaços e o saber- palavras, que tem a propriedade de amarrar, juntar os pedaços e formar o todo;

2.3. palavras que, em sendo o todo, ao significarem referem-se alusivamente ao saber.

3. Essência

3.1. pedaços são partes que se condensam pela amarração, articulação da linha escura;

3.2. palavras - todo que, articulado pela ação mediadora da linha escura, tem significado;

escuro - lugar contraditório que, pelo jogo alusivo, forma o inteiro com pedaços. Assemelha-se a um jogo cuja estratégia lança luzes sobre a sombra ou não significado, para o menino-narrador adulto, da palavra morfina e que ao ser iluminada, ou aludida faz com que ele tenha medo do depois.

Compreender e interpretar uma obra, é fazê-lo mediatizado pelas relações sociais, pela linguagem, pelas relações autor-leitor, pelos movimentos significativos de 1) fenômeno, 2) mediação e 3) essência, usando a alusão como uma das estratégias textuais da obra.

As operações particulares da alusão são aquelas operações conceituais que articulam o processo metafórico e o processo metonímico. $\mathrm{O}$ autor-modelo e o leitor-modelo constituem-se como ações que estabelecem o movimento parte/todo, inerente a essas categorias.

As categorias da metonímia e da metáfora, mais que figuras de linguagem, aludem à heterogeneidade constitutiva na re-construção lingüístico-semântica do movimento de sentido da alusão.

Pela metonímia, temos o movimento de deslocamento, em que o todo se desloca, em partes, fragmentos dele. A metáfora, pela condensação das partes, dos fragmentos formará o todo. Tais movimentos permitem e solicitam que o leitor vá mais longe na produção do sentido. 
A metáfora é a possibilidade que a linguagem oferece de se descobrir semelhanças. A metáfora, pela condensação, atuaria na linha da reprodução da relação todo/parte, a parte se identificaria com o todo. A reprodução não anularia a contradição. Mascararia a divisão e como tal se sujeita à ação da contradição. É uma estratégia que determina, no presente, o sentido do passado, com a memória, na perspectiva benjaminiana. Segundo Gagnebin (1997) “em outras palavras, as semelhanças não existem em si, imutáveis e eternas, mas são descobertas e inventariadas pelo conhecimento humano de maneira diferente, de acordo com as épocas".

$\mathrm{Na}$ metáfora, a parte é produzida para ser equivalente ao todo, de forma que a relação todo/parte, ou parte/todo possa ser vista pretensamente na condensação do todo, mas contraditoriamente, a parte jamais suprime a diferença entre as partes que concorrem ao lugar do todo (abriga a heterogeneidade, a diferença).

As palavras eram feitas de pedaços, e cabia à gente juntá-los. No escuro com linha escura e cautela, eu ia amarrando as letras, somando as partes com cuidado, sem pensar na palavra morfina, para não me aborrecer. E minha mãe cada dia mais mofina andava sem força para cantar e espantar o pavor (Idem, p. 38).

O giz, em sua mão, mais parecia um pedaço de varinha mágica de fada, explicando os mistérios. E, se economizava o quadro, para caber todo o ponto, nós também aproveitávamos bem as margens do caderno, escrevendo nas beiradinhas das folhas (Idem, p. 45).

Em minha casa, um par servia para dois. [...] Cabia enfiar um pedaço de papel enrolado nas pontas, tapeando a pobreza (Idem, p. 51).

Se a alusão à pobreza se faz com a parte, ou "com um pedaço de papel enrolado nas pontas", num movimento metonímico de deslocamento do sentido, por ação metafórica, ganha-se o movimento da condensação e, assim, o "pedaço de papel enrolado nas pontas" alcançaria o sentido de todo que indicia a metáfora da situação de pobreza. É, assim que se explica o movimento conceitual da alusão, ainda que parcialmente caracterizado de parte que se desloca de um todo a que é, em retorno, remetida, formando a ambigüidade em que é tecida a ação do autormodelo e do leitor-modelo. Tal ação vem marcada pelo silêncio e pelo não-silêncio da condensação metafórica (todo) e o deslocamento da metonímia (parte), com a alusão.

Mas a alusão ainda articula, intertextualmente, a relação de um fragmento de texto com o fragmento de outros textos ou interações textuais:

Parecia muito pequeno o ideal de meu pai, naquele tempo, lá. A escola onde me matriculou também na caixa escolar - para ter direito a uniforme e merenda devia me ensinar a ler, escrever e fazer conta de cabeça. O resto, dizia ele, é só ter gratidão, e isso se aprende copiando exemplos (Idem, p. 7).

Se queria dizer "eu gosto muito de doce" como a Lili que olhava para mim, ficava assim: "ou geste muare do deco" (Idem, p. 71). 
Interessante observar que a intertextualidade presente em Bartolomeu alude a fragmentos de outros textos mas também a seus próprios textos: o fragmento acima é parte não apenas da cartilha de alfabetização - Lili - mas também é mencionada em seu livro Ciganos: "Mas seu primeiro amor foi Lili. Ela era feita de papel, impressa na cartilha, mas que lhe permitia repetir o avesso: Lili, olhe para mim." Também, este fragmento remete aos registros encontrados nas cavernas pré-históricas, e ainda, a seu livro Porparte de pai.

Eu lembrava da casa de meu avô e suas paredes cobertas de recados, mas minha cabeça não sabia combinar (QUEIRÓS, 1995, p. 38).

- A entrada das minas de Salomão lá está. Chegaremos nós lá? (Idem, p. 51).

Em Ciganos há alusões ao livro citado à medida que o povo cigano também busca riquezas, corre riscos, desvenda mistérios, está em busca de desvendar o segredo da minas, já que são também feiticeiros e videntes que o guardam "[...] se tiveram notícias, pelas cartas do baralho, das minas de ouro do rei Salomão" (p. 11).

Outros falavam que vinham das terras de Espanha ou das areias de Portugal. Cortaram o mar guiados pelo brilho das escamas de sereias, escondidos nas noites.Sem saber ao certo de onde viam ou para onde iam, sei que os ciganos surgiam (QUEIRÓS, 1999, p. 1).

Ciganos nos possibilita várias leituras: uma, que poderia se considerada convencional e outras que seriam a história dos ciganos, a história do menino e a história de um e outro que se entrecruzam. E como graficamente cada página parece ser dividida por uma linha imaginária, o que indicia essas possibilidades de leituras e sentidos, abaixo da linha gráfica está o sonho soturno do menino-narrador adulto em busca de preencher a sua falta interior. Um menino feito de coragem e medo que enxergava nos ciganos a possibilidade que estes ocupassem o vazio que ele carrega dentro de si.

Foi no tempo dos ciganos que o conheci. Ele era como a madrugada perto de acordar.

Era um menino feito de coragem e medo (Idem, p. 1, grifo nosso).

$A$, ser roubado era o mesmo que ser amado. Ele sentia que só roubamos o que nos faz falta. E ele - como gostaria de ser ausência, mesmo dos ciganos (Idem, p. 7, grifo nosso).

Para um menino, assim só, os ciganos eram uma espécie de sol que acordava os afetos (Idem, p. 8, grifo nosso).

Percebo, nos excertos, que o menino constrói uma imagem dos ciganos de "espécie de sol que acordava os afetos", contrariando uma memória social que se organiza em torno de um mito de que o povo cigano, nômade é aquele que rouba objetos, rouba meninos e tem um modo de existir que causa medo. Mas “Ah, ser 
roubado era o mesmo que ser amado", aqui o verbo "roubar" assume um significado positivo, contrário ao seu significado real de retirar algo de outrem indevidamente. Para um menino que convivia com tantas faltas; maus-tratos do pai, perda da mãe, solidão, só os ciganos, com tanta alegria que despertam na cidade, eram capazes de preencher seu vazio. Por isso ele queria ser levado/roubado pelos ciganos. Desejava desfrutar de outros mundos com outras companhias. Para ele "os ciganos eram uma espécie de sol que acordava os afetos".

Segundo Campos (2005, p. 175-76),

[...] A fonte de um texto é, pois, um ponto cuja origem está na relação com outros pontos, outros textos: a fonte de um texto está nos pontos relacionais. Já que o texto é uma realização concreta da mediação, ou da determinação recíproca dos agentes que o constituem como ponte, o autor ou o leitor podem escrever e ler usando o estilo de jogar com os pontos relacionais que fazem nascer o texto: as relações intertextuais que o constituem como objeto de interação autor/leitor.

A alusão articula um texto com a dimensão constitutiva de outro texto enquanto heterogeneidade e também, discursivamente, o interdiscurso como constituinte que determina, dialogicamente o intradiscurso, pois segundo Chauí (apud BOSI, 1979): “[...] ler é senão aprender a pensar na esteira deixada pelo pensamento do outro. É retomar a reflexão de outrem como matéria-prima para o trabalho de nossa própria reflexão".

As palavras eram feitas de pedaços, e cabia à gente juntá-los. No escuro com linha escura e cautela, eu ia amarrando as letras, somando as partes com cuidado, sem pensar na palavra morfina, para não me aborrecer. E minha mãe cada ida mais mofina andava sem força para cantar e espantar o pavor (QUEIRÓS, 1997, p. 36-8).

Outro corpus de minha investigação - O risco do bordado, de Autran Dourado, é ambientado na mítica Duas Pontes, cidade a que retornaria em outros livros, como uma síntese do universo interiorano de seus personagens. É o relato de uma viagem ao passado do escritor João da Fonseca Ribeiro, que volta ao cenário de sua infância. Ao encontrar antigos moradores da cidade, parentes e companheiros de infância, ele vai montando uma espécie de quebra-cabeças entre o vivido e o imaginado, completando e expandindo fragmentos de memória que são a narrativa de sua infância e adolescência.

Como num típico romance de formação, em que o principal interesse está no crescimento e desenvolvimento do protagonista, o leitor vai sabendo, aos poucos, como João se tornou o que é, sua dura trajetória na descoberta da sexualidade, da amizade, da traição e, também, da literatura. Prostitutas, jagunços, antepassados mortos, parentes velhos, figuras características de Duas Pontes cruzam o caminho 
de João, que desta forma vai enxergando, retrospectivamente, o risco sob o bordado que, afinal, é a sua própria história de vida:

Vovô Tomé tinha um faro todo especial para avaliar qualidade de circo, não errava nunca. Este é dos bons, dizia ele. Este não é lá essas coisas. Conforme o mastro.

O mastro erguido, a lona esticada, vovô Tomé ficava feliz da vida, feito o dono do circo. Aquilo deixava de ser circo, era um navio antigo, vovô Tomé deixava de ser fazendeiro, virava armador de navio, dono de todos os mares.

Isso foi depois quando eu lia os livros de aventura e comparava, me lembrando dos tempos de quando a gente ia ver armar circo, eu muito menininho ainda; depois, quando comecei a ler os livros da coleção Terramarear no grêmio do Colégio São Mateus, e me lembrava de vovô Tomé, de vovó Naninha, de mamãe, o coração miúdo de saudade. Eu tinha então - no tempo da comparação - dezesseis, vamos dizer dezessete anos, não sei ao certo, só fazendo as contas, e não ia mais ao circo com vovô Tomé por causa de Zito e da rapaziada alegre, como foi o caso do Circo Milano, dos irmãos Ramurazzi, dom Arcângelo e dos Cirino, da valente Valentina, desta história que agora vou lembrando, aos poucos recuperando como um bicho-da-seda ou uma aranha vai tirando de si o fio da própria teia... (DOURADO, 1999, p. 67-68).

Em um primeiro momento, veja-se a projeção da excedência de visão de João ao construir um vovô Tomé, parecendo um pouco menino, ou resgatando em si o menino que nele vive, via memória-sonho: um vovô Tomé que se deslumbra com o circo e com o que ele lhe traz nos seus sonhos, através do tamanho do mastro - signo que identifica sua maior ou menor importância como lugar de espetáculo.

Por outro lado também, o mastro significa, na capacidade de sonhar de vovô Tomé, o poder transformar-se num armador, dono de todos os mares - aquele que com suas naus singra mares e nas idas e vindas podendo fazer seus relatos de viagens.

No plano da Enunciação I, temos o circo que é o constituinte da dimensão das coisas acontecidas (+); o espetáculo que ele promete pertence à Enunciação II (-) coisas não acontecidas; o tamanho do mastro e a lona indiciadores de seu poder de conquista do público.

$\mathrm{Na}$ Enunciação II, ou seja, o constituinte da alusão que se acrescenta, com a memória-sonho, na qualidade de dispersão, quando o circo se transforma em navio, com o que Vovô Tomé alimenta o seu poder sonhar: ser "armador" da palavra que poderia mudar-lhe a rota, na determinação recíproca de I e de II, gerando III, quando os sentidos do acontecido e do não-acontecido presentes no circo passam a ser abertos pelo não-acontecido e acontecido que se mostram na figura do navio que alude a circo, ou do circo que alude a navio. $\mathrm{Na}$ interlocução com I e II encontramos a aranha que tira de si o fio da própria teia. Ou seja, o fio como produto e 202 A Cor das Letras - UEFS, n. 8, 2007 
processo de produção do sentido, possibilita que as tradições de circo e navio possam ser mescladas em III no jogo que, em giro permite que em III - navio mesclado de circo - aconteça a presença de I e II enquanto objetos reunidos pela memória-trabalho, ainda que possam ser dispersos pela memória-sonho.

Assim pensando, a alusão só nasce no momento III, ou seja, o conceito de alusão ocorre na determinação recíproca de I e II, com a sua ultrapassagem dessa determinação e com a sua condensação em III.

A hipótese que tenho procurado confirmar nas pesquisas tem me indiciado que é a alusão uma estratégia de leitura, pesquisa e investigação que permite o diálogo do universal com o regional, do oral com o escrito, e vice-versa, no romance. O caráter mimético, no dizer de Benjamin (apud GAGNEBIN, 1997), possibilita a produção do sentido do texto como experiência mutável e permite, por isso, a elaboração de um outro texto por parte de leitor. Ou seja, o risco não é o bordado e este não será inteiramente conhecido: são pontos, ou histórias, em relação e em construção.

Assim, para concluir, considerando-se as relações intertextuais, a alusão é a perspectiva teórica que, ao delinear o projeto de leitor-modelo, ou certo estilo de escrita, é um produto que fala ou alude, ao mesmo tempo, com as mediações de acesso à obra, do processo.

\section{REFERÊNCIAS}

AUTHIER-REVUZ, J. Heterogeneite montrée et heterogeneite constitutive: elements pour une aproche de l'autre dans le discours. In: ORLANDI, E.; GERALDI, J. W. (Org.). Cadernos de Estudos Lingüísticos - O discurso e suas análises. Campinas: UNICAMP, v. 19, p. 25-42, jul./dez 1990.

BAKHTIN, Mikhail. Estética da criação verbal. Trad. Pereira Maria E. Galvão. 2. ed. São Paulo: Martins Fontes, 1997.

BAKHTIN, Mikhail. Marxismo e filosofia da linguagem. Trad. Michel Lauhd e Yara Frateschi Vieira. 8. ed. São Paulo: HUCITEC, 1997.

BAKHTIN, Mikhail. O problema do conteúdo, do material e da forma na criação literária. In: Id. Questões de Literatura e de Estética - a teoria do romance. 4. ed. São Paulo: HUCITEC, 1998.

BOSI, E. Memória e sociedade: lembranças dos velhos. São Paulo: Cia. das Letras, 1979.

CAMPOS, Edson Nascimento; CURY, M. Zilda Ferreira. Fontes primárias: saberes em movimento. Rev. Fac. Educ., São Paulo, v. 23, n. 1-2, jan./dez. 1997.

CAMPOS, Edson Nascimento. A relação entre o produto e o processo na escrita do texto. Educação em Revista, Belo Horizonte, v. 2, n. 3, 1986.

CAMPOS, Edson Nascimento. Memória e escola: a produção de sentido na redação. (Dissertação Mestrado em Educação). Belo Horizonte: Faculdade de Educação/UFMG, 1988. 
CURY, Maria Zilda. Escrever e ler: faces da mesma moeda. Vertentes: Revista da Fundação de Ensino Superior de São João del-Rei, São João del-Rei, n. 9, p. 75-83, 1997.

CURY, Maria Zilda. Intertextualidade: uma prática contraditória. In: COELHO, Haydée Ribeiro; CASANOVA, Vera. (Org.). Ensaios de semiótica: cadernos de lingüística e teoria da literatura. Belo Horizonte: UFMG/FALE, n. 8, p. 117-128, dez. 1982.

DOURADO, Autran. O risco do bordado. Rio de Janeiro: Rocco, 1999.

ECO, Umberto. Seis passeios pelo bosque da fição. Trad. Hildegard Feist. São Paulo: Cia. das Letras, 1994.

GAGNEBIN, J. Marie. Sete aulas sobre linguagem - memória e história. São Paulo: Imago, 1997.

GAGNEBIN, J. Marie. História e narração em Walter Benjamin. 2. ed. São Paulo: Perspectiva, 1999.

GAGNEBIN, J. Marie. Atenção e dispersão: elementos para uma discussão sobre arte contemporânea entre Benjamin e Adorno. Palestra - Congresso Internacional de Teoria Estética. Belo Horizonte: FAFICH/UFMG, 2003.

KOSIK, Karel. Dialética do concreto. Trad. Célia Neves e Alderico Toríbio. 6. reimpr. São Paulo: Paz e Terra, 1995.

QUEIRÓS, Bartolomeu Campos. Ciganos. 12. ed. Belo Horizonte: Miguilim, 1999.

QUEIRÓS, Bartolomeu Campos. Ler, escrever e fazer conta de cabeça. 2. ed. Belo Horizonte: Miguilim, 1997.

QUEIRÓS, Bartolomeu Campos. Por parte de pai. Belo Horizonte: RHJ, 1995.

TORGA, Vânia L. M. O movimento de sentido da alusão: uma estratégia textual de leitura do livro "Ler, escrever e fazer conta de cabeça", de Bartolomeu Campos Queirós. (Dissertação: Mestrado em Estudos Lingüísticos). FALE/UFMG, Belo Horizonte, 2001. 